\title{
运用交互式电子白板 构建高效数学课堂
}

\author{
王秀芳 \\ 福清市实验小学 \\ DOI:10.32629/er.v2i4.1761
}

[摘 要] 交互式白板教学的运用是一种高效的现代教学方法,对学生的主体性,创新意识和探索精神的发展起着重要作用。在 小学数学教学中使用交互式白板是小学数学课堂发展的必然趋势。它必将激发学生的学习兴趣,改进教师的教学方法和学生 的学习方式,最终优化小学数学课堂教学。

[关键词] 交互式电子白板; 提高几何直观能力; 高效课堂

数学课堂使用交互式电子白板是现代教育技术手段的 新形式, 为师生互动、生生互动提供了技术支撑。交互式电 子白板不但方便、灵活, 而且能优化数学课堂, 提高学生几何 直观能力。下面我就浅谈交互式电子白板在构建小学数学高 效课堂中的一些应用优势。

\section{1 巧用交互式电子白板,妙设课堂情境}

情境教学主要是以生动形象的问题情境激起学生学习 情绪的一种教学方法。在数学教学中, 我们利用电子白板的 特点, 展示出优美的画面、迷人的场景、动感的影像、辅之 以动听的音乐, 让学生感受、赏析、发现美, 激发学生学习的 兴趣, 进而探究知识, 并且在探究知识的过程中生成知识。在 此过程中进而拨动他们追求 “真、善、美” 的 “情弦” , 陶 治性情, 塑造良好的个性品质。

例如: 在讲授《轴对称图形》一课时, 我创设了这样的 情境, 先让学生初步感受美、赏析美。白板展示: 美丽的郊 外, 五颜六色的风筝迎风招展; 花从中, 一只只蝴蝶翩翩飞 舞; 天空中, 时不时地划过银白色的飞机, 留下美丽的弧 线……适时插入: 同学们, 这些图形为什么如此美呢? 就 在于它们的美有着共同的秘密: 轴对称。从而自然而然引出 这一节课的教学目标: 什么轴对称图形。接着利用电子白板 的手写文本识别功能, 板书课题, 方便有效地创设情景, 优化 课堂导入。

\section{2 巧用交互式电子白板, 促进多维互动}

著名数学教育家波利亚曾指出, “数学有两个侧面, 一方 面是欧几里得式的严谨科学, 从这个方面看, 数学像一门系 统的演绎科学; 但是另一方面, 在创造过程中, 数学更像是一 门实验性的归纳科学。” 人的思维就是形象思维在前, 抽象思 维在后。特别是中低年级的学生, 学生对一些直观的事物比 较感兴趣。这就需要我们教师在教学中尽量用图片、实物等, 并将动与静结合起来, 通过生动有趣的画面使静态的知识动 态化, 把抽象的概念形象化, 从而帮助学生掌握知识。

例如: 在教学《梯形的面积》这课, 难点在于梯形面积 的推导, 我用交互式电子白板向学生展示探索面积公式的 全过程: 在白板上画出一个梯形, 接着再克隆一个梯形, 然后 让学生通过对其中一个梯形的旋转和平移, 把这两个完全一
样的梯形拼成一个大的平行四边形。学生在操作和观察的过 程中体会到这个大的平行四边形面积是原来梯形面积的 2 倍, 有学生提出如果是直角梯形呢? 我立马在白板上又画出 一个直角梯形, 接着就有学生上台根据刚才的学法迁移, 用 2 个完全一样的直角梯形可以拼成一个长方形, 从而推导出梯 形的面积计算公式。利用电子白板的回放页面的功能还可反 复演示几遍这个探索的过程, 加深学生对探索过程的理解, 以及对面积计算公式的掌握和巩固。交互式电子白板, 能够 把知识结论的形成过程像剥洋苟似的带领学生一层一层地 剖析, 而且学生能以主人翁的角色自助式地上台参与操作、 尝试, 在参与的过程中, 观察能力、思考能力、操作能力都得 到锻炼, 学生的学习劲头就更足了。

再如: 在教学《长方体的表面积》时, 我在电子白板上 画一个普通的长方体和一个特殊的长方体 (有 2 个相对面是 正方形的), 并利用展开功能, 直观地把长方体 6 个面展开, 通过学生观察比较, 合作交流, 得出长方体面的各种特征, 从 而推导出长方体表面积的计算公式, 掌握了新知。

\section{3 巧用交互式电子白板,培养自主探究}

培养学生自主探究是《新课程标准》的一个显著特征, 也是基本要求。

交互式电子白板改变了单一的对着课件一页一页地讲 解的形式, 有利于把呆板的按事先设定的课堂模式变成能根 据课堂实际情况临时生成的灵动的课堂模式。交互式电子白 板更加智能化, 更便于教师操作, 并且让教师和学生、学生和 学生之间的互动形式更加多样, 让课堂更加有趣开放, 无形 中提高了学生参与学习的动力。交互式电子白板的图形克隆 和移动功能很适合用于数学课上有关分类知识的教学。比 如: 在《三角形的分类》一课中, 利用传统课件的话, 很难把 学生将三角形分类的过程及不同学生的不同方案展示出来, 更无法将学生不完善的方案优化调整的过程展示出来。而用 上交互式电子白板, 这些问题都迎刃而解了。教师先呈现要 分类的三角形, 接着让学生上台通过克隆拖拽图形将图形进 行分类, 尤其是由于强大的克隆功能可以让学生各种不同的 分类方法一一呈现在屏幕上, 这样便于学生对各种方法进行 分析比较。其中比较典型的是学生将三角形分成两类, 即有 
直角的三角形为一类, 没有直角的三角形为一类。教师引导 学生将这种分法与正确的分法进行比较, 发现没有直角的那 些三角形中还包含两种不同的三角形, 即一种三角形全是锐 角, 另一种三角形中除了有锐角还有钝角, 因此, 要把这一类 三角形中的两种三角形再分开, 这样, 自然而然就得出了正 确的分法。学生不仅明白了为什么不能将三角形分两类, 还 明白了怎样将两类分法调整为三类分法, 从而将分类的方法 理解得更加透彻。通过学生在白板上自主探究、实践, 亲自 验证自己的想法, 这样灵动的学习方式, 不但激发了学生的 思维, 还能让孩子的思维得到更好地碰撞, 在自主探究中建 构了知识。

\section{4 运用交互式电子白板, 巧妙突破难点}

交互式电子白板可以对一些抽象的概念进行直观演示, 实 时进行师生互动、生生互动, 在互动中突破教学中的重难点。

例如: 教学《平行与垂直》, 我是运用交互式电子白板, 直观突破难点, 让孩子亲身经历知识发生发展形成的整个过 程, 提高了学生几何直观能力。具体操作如下:

首先, 我先出示 8 组直线让学生进行分类, 学生上台通 过拖拽功能进行分类, 对学生的分类情况进行截屏, 不同的 学生会有不同的分类, 结果通过直观比较导入教学。

其次, 对平行线的本质特征进行探索, 我同时拖动两条 直线任意延长都不相交。这样学生就直观地理解平行线的概 念, 在此基础, 我进行旋转, 便问学生他们还会平行吗? 这些 平行有什么共同特征, 学生自然而然就有了疑惑, 学生带着 这些疑惑通过进一步探究, 发现他们之间距离处处相等。

最后, 平行与垂直的难点, 是对同一平面的理解, 我从摆 两根小棒到立交桥上面两辆行驶的路线再到电子白板的直 观教学, 让学生观察, 这两条直线既不相交, 也不平行, 这是 怎么回事呢? 学生产生了新知冲突, 通过交互式白板的功能 演示, 让学生明白了, 因为不在同一平面上的两条直线既不 相交也不平行, 而今天我们研究的是在同一平面内的两条直 线不平行延长后自然会相交。电子白板打破了传统的教学模 式, 将抽象问题转化为直观问题, 使教学内容更加生动。

\section{5 巧用交互式电子白板,深化课堂练习}

练习是把知识转化为能力并发展智力的活动。传统的教
学在学生练习和教师展示不同练习方法时有许多局限, 例如 在教学《搭配中的学问》时, 我曾经为了展示出多种的拼法 而要加班用卡纸为班上每个小组制作了几套不同的衣服, 然 后让学生拼一拼, 摆一摆, 费时也费力。有了交互式电子白板, 便可以让学生到白板上把自己搭配的方法给同学们演示一 下? 台下的同学一起帮他数一数。这个环节, 学生可以直接 将上衣和下装拖到右侧的方框内进行自由的搭配。学生与白 板间的互动能使学生身体力行地对数学内容进行操作。全班 的同学也能很清楚的理解白板前学生的思维过程, 有不同想 法的学生还可以继续上来展示, 丝毫不受前一个学生操作的 影响。既节约了时间, 又深化了课堂练习。

利用交互式电子白板, 还可以进行不同形式的练习, 如: 游戏、选择、填充、拼图等形式, 也可以进行一题多变, 一题 多解的训练。

例如: 在教学完《长方体的表面积》后, 设计了学生喜欢 的 “挑战自我” 闯关游戏, 内容是计算各种变式表面积, 有计 算前后面、上下面、左右面、有无盖(底)、四周面、通风管 等表面积, 学生主动选择关卡, 纷纷抢着答题, 还经常当小老 师给同学们讲解, 这样, 一举多得, 不但让新知识掌握得更扎 实, 还让实践能力得到锻炼, 学生越学越有趣, 越学越爱学。

运用交互式电子白板教学是一种高效率的现代化教学 手段, 有助于学生对数学教学内容的掌握, 它对学生主体性 的发挥,创新意识和探索精神的培养都起着重要作用。但在 具体的教学过程中, 我们选用交互式电子白板时既要根据学 生的认识规律、心理特点、又要注意服从于学习目标、学生 学习实际等诸多因素。只有合理的使用交互式电子白板, 教 师 “教” 的主体地位才能得到加强, 学生 “学” 的主体地位 也才能得到充分的发展。

\section{[参考文献]}

[1]潘效,交互式电子白板在课堂教学中的应用策略 [J]. 中国电化教育,2010,(8):87.

[2]王克香.交互式电子白板在课堂教学中的应用探讨 [J].甘肃教育,2019,(02):84.

[3]陈丹.交互式电子白板在小学英语课堂教学中的应用 [J].教育信息技术,2018,(06):20-21+41. 